\title{
Influence of Encapsulated Nanodiamond Dispersion on P(3HB) Biocomposites Properties
}

\author{
Gabriel Rodrigues de Almeida Neto ${ }^{a, *}$, Mariana Valinhos Barcelos ${ }^{a}$, Rubén Jesus Sánchez Rodrí- \\ guez $^{a}$, José Gregório Cabrera Gomez ${ }^{b}$ \\ a Laboratório de Materiais Avançados - LAMAV, Universidade Estadual do Norte Fluminense - UENF, \\ Av. Alberto Lamego, 2000, 28015-620, Campos dos Goytacazes, RJ, Brazil \\ ${ }^{b}$ Instituto de Ciências Biomédicas, Universidade de São Paulo-USP, Av. Prof. Lineu Prestes, 1374, \\ 05508-900 São Paulo, SP, Brazil
}

Received: September 26, 2016; Revised: January 09, 2017; Accepted: March 29, 2017

\begin{abstract}
Studies regarding biodegradable nanocomposites to be used as orthopedics devices have been intensified. This work aims to investigate the influence of ND dispersion on thermal and mechanical properties of a biocomposite of poly(3-hydroxybutyrate) $(\mathrm{P}(3 \mathrm{HB})$ ) reinforced with nanodiamonds (ND) intended to be used as orthopedics devices, with advantages as biodegradability. In order to improve its dispersion, $\mathrm{P}(3 \mathrm{HB})$ has encapsulated ND in three different mass ratios: $\mathrm{P}(3 \mathrm{HB}): \mathrm{ND}(16: 1),(12: 1)$ and $(8: 1)$. However, for all formulations, NDs are presented as agglomerates, in different intensities. In order to relate the distribution of ND within the polymer matrix and biocomposite properties, TGA, DSC, and DMA analysis were done. The formulation with higher content of $\mathrm{ND}, \mathrm{P}(3 \mathrm{HB}): \mathrm{ND}(8: 1)$, presents larger aggregates; thus, decreasing its properties. With smaller and more distributed agglomerates, the 12:1 ratio composite displayed superior storage modulus and glass transition temperature, probably due to better polymer chain restriction.
\end{abstract}

Keywords: $P(3 H B)$, nanodiamond, biocomposite

\section{Introduction}

Macro-scale composites can have their properties optimized by replacing their filler with a nano-scaled reinforcement, which must have at least one dimension in the range of $1-100 \mathrm{~nm}$, the resulted material is defined as nanocomposites ${ }^{1,2}$. Nanocomposites may achieve superior properties than conventional composites because the reduced dimension of its particles promote a drastic increase in the superficial area to volume ratio, and consequently in the reinforcement/matrix interface, optimizing its properties, in addition to requiring smaller loading (percentage in weight) to achieve similar reinforcement. However, in order to achieve these benefits, the particles must be well distributed on the matrix ${ }^{3-5}$.

A viable nanocomposite application is to develop biomaterials. Even though it is a recent topic, biomaterials have been used for a long time. Nowadays, it is widely used in the medical industry. Metallic alloys as stainless steel, titanium and $\mathrm{Co}-\mathrm{Cr}$ alloys are the most common materials used as orthopedic fixation dispositive. However, they don't fully present all the desirable characteristics as: mechanical properties similar to the bone, in order not to stress-shield it; biocompatibility, not to cause an inflammation or toxic response; biodegradability, so that the dispositive will be integrated to the host bone structure and to eliminate the need of a second surgical procedure to remove them ${ }^{6}$.

* e-mail: 11gabrielrodrigues@gmail.com
Actually, they have a stiffness much higher than bone; $\mathrm{Co}-\mathrm{Cr}$ alloys and stainless steels are oxidized and release metallic ions that may provoke an inflammation; and they are not biodegradable ${ }^{7}$. An alternative to develop a material that meets all the requirements is to engineer a biodegradable polymer biocomposite reinforced with an inorganic particle. In addition to not requiring a second surgery to remove it, a biodegradable polymer can be designed to degrade at a rate that allows a progressive increment of load in the injured bone, decreasing the probability of a new fracture ${ }^{8}$; and act as a substrate for new bone tissue growth ${ }^{9}$.

Poly(3-hydroxybutyrate) $(\mathrm{P}(3 \mathrm{HB}))$ is a biodegradable polyester from the polyhydroxyalkanoate (PHA) family. It is a highly crystalline polymer, with properties similar to polypropylene (PP); however, its brittleness limits its application ${ }^{10}$. It is a promisor polymer for biomedical application. The $\mathrm{P}(3 \mathrm{HB})$ hydrolytic degradation product, D-(-)-3-hydroxybutyric acid, is an usual metabolite in all living beings ${ }^{11}$. Different from the others biodegradable polymers, $\mathrm{P}(3 \mathrm{HB})$ doesn't change the region $\mathrm{pH}$ while being degradaded ${ }^{12}$. However, it has a slow degradation rate ${ }^{13}$. Doyle, Tanner and Bonfield demonstrated that it has a good tissue adaptation response and no inflammatory response after up to 12 months $^{14}$. Gredes et al. concluded that $\mathrm{P}(3 \mathrm{HB})$ patches presented an osteoconductive behavior ${ }^{15}$.

Nanodiamond (ND) has been attracting large interest, since it is has a large-scale production, low-cost associated and unique properties ${ }^{16}$. It is known for its superior hardness, high 
mechanical properties, biocompatibility - the highest among carbon-based material, low toxicity, chemical stability and high thermal conductivity ${ }^{17-19}$. It has been studied for different applications as abrasive pastes ${ }^{20}$, wear-resistant coating ${ }^{21}$ and UV protection flms ${ }^{22}$. Due to it biocompatibility, it has been also studied for drug-delivery ${ }^{23}$ and as reinforcement in biocomposites ${ }^{24}$.

Few authors have investigated the addition of nanoparticles of diamond (ND) on thermoplastic biodegradable matrix. Zhang et al. functionalized ND by covalently attaching octadecylamine on its surface and added it in a poly(Llactic acid) (PLLA) solution, in order to formulate films by solvent evaporation methodology. The addition of $10 \mathrm{wt} \%$ of ND increased more than $200 \%$ on Young's modulus and $800 \%$ on hardness, obtained by nano and Vickers identation ${ }^{5}$. Compressed molded samples of PLLA with $10 \mathrm{wt} \% \mathrm{ND}$ increased $280 \%$ in strain to failure and $310 \%$ in fracture energy $^{25}$. Zhao et. al found the addition of ND on poly(lactic acid) (PLA) to increase dynamic mechanical properties on injection molded samples ${ }^{26}$. The influence of ND on PCL electrospinning fibers ${ }^{27}$ and poly(LLA-co-CL) films ${ }^{28}$ was also investigated by other authors. However, no published paper studying the incorporation of $\mathrm{ND}$ on $\mathrm{P}(3 \mathrm{HB})$ or any of the PHA polymers was found.

This work aims to develop a nanocomposite of $\mathrm{P}(3 \mathrm{HB})$ reinforced by ND. To study the influence of ND distribution on the thermal and mechanical properties and obtain a formulation that optimize the biocomposite properties in order to be used as bone grafts and orthopedics devices (internal fixation devices, e.g., screw, plate and suture anchor).

\section{Materials and Methods}

\subsection{Materials}

In this work, both chloroform $\left(\mathrm{C}_{2} \mathrm{H}_{6} \mathrm{O}\right) \mathrm{PA}(99.8 \%)$ and ethylic alcohol $\left(\mathrm{CHCl}_{3}\right)(95 \%)$ were acquired from VETEC, Sigma-Aldrich. The nanoparticles of detonation diamond (ND), DYK-J, were purchased from Diambra diamantes, with a diameter range of 2-250nm and specific surface area of $15 \mathrm{~m}^{2} / \mathrm{g}$. The $\mathrm{P}(3 \mathrm{HB})$ obtained as powder, was synthetized by PHB Indústria, claimed to have a molecular weight $\left(\mathrm{M}_{\mathrm{w}}\right)$ of 600,000 Dalton, density of $1.20-1.24 \mathrm{~g} / \mathrm{cm}^{3}$ and melting temperature of $175^{\circ} \mathrm{C}$.

\subsection{Nanocomposite preparation}

The polymer underwent a purification process on chloroform under reflux for $10 \mathrm{~h}$, precipitated in ethylic alcohol at $0^{\circ} \mathrm{C}$, and dried at $60^{\circ} \mathrm{C}$ for $4 \mathrm{~h}$ or until further solvent is evaporated. The ND were encapsulated by $\mathrm{P}(3 \mathrm{HB})$, in an attempt to improve the particles dispersion on the polymeric matrix. The methodology is being patented. To encapsulate the particles, a solution of $4 \mathrm{~g}$ of $\mathrm{P}(3 \mathrm{HB})$ and $150 \mathrm{~mL}$ chloroform was homogenized. Afterwards, the ND was added to the solution in three mass ratios: $\mathrm{P}(3 \mathrm{HB})$ : ND (16:1), (12:1) and (8:1). Then, each solution was evaporated, encapsulating the nanoparticles, according to the methodology.

\subsection{Specimen preparation}

A mass of $1.85 \mathrm{~g}$ of the previously encapsulated material was added to the mold and manually compacted. The mold was placed on a hydraulic press (Marcone MA 098/A) heated to $150^{\circ} \mathrm{C}$, aided by a lateral heating ring and compaction force of 6.5 ton. The specimen final dimension is $35 \times 10 \times 4 \mathrm{~mm}$.

\subsection{Characterization}

$\mathrm{P}(3 \mathrm{HB})$ viscosimetric molecular weight was determined by Mark-Houwink equation (Equation 1), using a CannonFenske viscometer immersed in a thermal bath at $30^{\circ} \mathrm{C}$ using chloroform as solvent. Five solution concentration and five readings were used to determine the viscosimetric properties.

$$
[\eta]=K M^{\alpha}
$$

Where [ $\eta$ ] is the intrinsic viscosity, $K$ and $\alpha$ are constants for a given solution at a determined temperature; $\mathrm{K}=0.0118 \mathrm{~mL} / \mathrm{g}$ and $\alpha=0.78$, determined by Akita et. al, was used ${ }^{29}$.

Some analyses were done in order to investigate the effect of different loads of ND over the thermal and mechanical properties: Differential Scanning Calorimetry (DSC), performed using a TA-Instruments DSC Q2000, at a heating rate of $10^{\circ} \mathrm{C} / \mathrm{min}$ and under a nitrogen atmosphere of $20 \mathrm{~mL} /$ min; Thermogravimetric Analysis (TGA), performed using a TA-Instruments TGA Q5000 at a heating rate of $10^{\circ} \mathrm{C} / \mathrm{min}$ and nitrogen flow rate of $100 \mathrm{~mL} / \mathrm{min}$; Dynamic Mechanical Analysis (DMA), performed using a TA-Instruments DMA $\mathrm{Q} 800$, at an oscillation amplitude of $10 \mu \mathrm{m}$, frequency of $1 \mathrm{~Hz}$ and heating rate of $3^{\circ} \mathrm{C} / \mathrm{min}$, using a three-point bending clamp.

The micrographs of the samples fracture surface after mechanical testing were obtained using a Shimadzu SSX550 Scanning Electron Microscope (SEM); used to evaluate the ND morphology, distribution and agglomeration on the fracture surface. Then, correlate it with previous results of thermal and mechanical analyses.

\section{Results and Discussions}

The $\mathrm{P}(3 \mathrm{HB})$ molecular weight obtained by viscometry was $49,084 \mathrm{~g} / \mathrm{mol}$. In order to evaluate the effect of adding $\mathrm{ND}$ in a matrix of $\mathrm{P}(3 \mathrm{HB})$, thermal and mechanical analyses were done. Aided by the micrographs done by SEM, it was able to correlate the results of the analyses with the distribution of ND in the $\mathrm{P}(3 \mathrm{HB})$ matrix.

A sample of each composition was taken out from its specimen and analyzed by TGA, aiming to investigate the 
influence of different loads of ND on the composite thermal behavior; the resulted curve is shown in Figure 1. For all formulation, its weight start to decrease at $230^{\circ} \mathrm{C}$ and from $300^{\circ} \mathrm{C}$ on there is no significant change on weight. This range of temperature, which occurred loss of weight, correspond to $\mathrm{P}(3 \mathrm{HB})$ degradation, and it is the same range for all formulation. On the curve of derivative weight loss per temperature, the formulations presented the same behavior, displaying its peak (the highest rate of weight loss) at the same temperature. It can be concluded that the variation of ND load, for the analyzed formulation, does not modify both the $\mathrm{P}(3 \mathrm{HB})$ rate of weight loss and range of temperature that it degrades. However, all formulations peak of weight loss rate compared to raw $\mathrm{P}(3 \mathrm{HB})$ are shifted to lower temperatures. It can be due ND lower specific heat capacity $\left(\mathrm{C}_{\mathrm{p}}\right): 3.98 \pm 0.20$ $\mathrm{J} / \mathrm{cm}^{3} \cdot \mathrm{K}$ and $1.6 \mathrm{~J} / \mathrm{cm}^{3} . \mathrm{K}$, of $\mathrm{PHB}^{30}$ and $\mathrm{ND}^{31}$, respectively. PHB has a $\mathrm{C}_{\mathrm{p}}$ more than two-fold higher than ND.

TGA was also used to determine the percentage in mass of ND on the sample analyzed. The values are presented on Table 1. There is a significant difference between the percentage of ND on the solution before encapsulation and on the sample analyzed. This difference may be due loss of material during encapsulation process and heterogeneous distribution of ND in $\mathrm{P}(3 \mathrm{HB})$ matrix, as it was confirmed by SEM micrographs; therefore is possible that the sample taken out from the specimen may correspond to the region poor of ND. In order to confirm the heterogeneous distribution of ND, two additional samples from different specimen regions of each formulation (referred as region $\mathrm{A}, \mathrm{B}$ and $\mathrm{C}$ ) were also analyzed, as shown in Figure 2. The ND content present in different regions of $\mathrm{P}(3 \mathrm{HB}): \mathrm{ND}(8: 1)$ are: $7.2 \mathrm{wt} \%$, $4.7 \mathrm{wt} \%$ and $3.4 \mathrm{wt} \%$, for regions $\mathrm{A}, \mathrm{B}$ and $\mathrm{C}$, respectively.

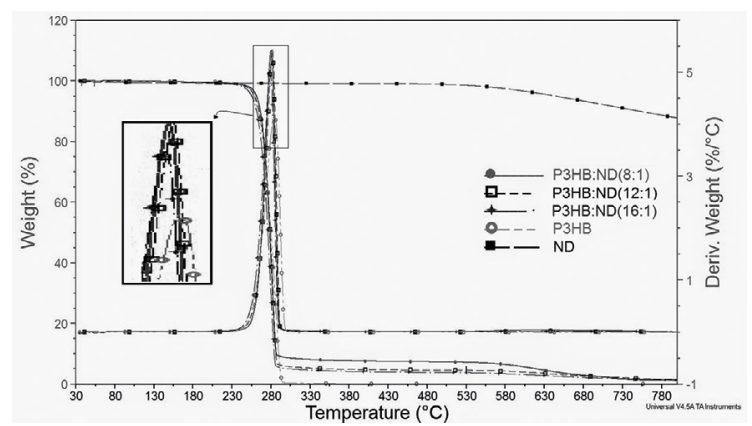

Figure 1: TGA curve for the three distinct formulation (green curve: $\mathrm{P}(3 \mathrm{HB})$ :ND(8:1); blue: $\mathrm{P}(3 \mathrm{HB}): \mathrm{ND}(12: 1)$; purple: $\mathrm{P}(3 \mathrm{HB}): \mathrm{ND}(16: 1)$ ).

Table 1: Comparison of ND load for each formulation presented by TGA and on the solution before encapsulation.

\begin{tabular}{lcc}
\hline Formulation & $\begin{array}{c}\text { ND load } \\
(\mathrm{wt} \%)(\mathrm{TGA})\end{array}$ & $\begin{array}{c}\text { ND load } \\
\text { (wt\%) (Before } \\
\text { encapsulation) }\end{array}$ \\
\hline $\mathrm{P}(3 \mathrm{HB}): \mathrm{ND}(16: 1)$ & 7.2 & 12.5 \\
$\mathrm{P}(3 \mathrm{HB}): \mathrm{ND}(12: 1)$ & 4.6 & 8.3 \\
$\mathrm{P}(3 \mathrm{HB}): \mathrm{ND}(8: 1)$ & 3.8 & 6.2 \\
\hline
\end{tabular}

Crystallinity is a property very important for a polymer; it influences their mechanical and thermal properties. DSC analysis can be used to determine it, through obtaining its melting enthalpy $\left(\Delta \mathrm{H}_{\mathrm{m}}\right)$, which is calculated upon the area under the polymer melting peak on the DSC curve.

The melting enthalpy, melting temperature and crystallinity for the three formulations and raw $\mathrm{P}(3 \mathrm{HB})$ taken from the DSC curve are shown on Table 2 . To calculate the crystallinity, the following equation was used ${ }^{32}$ :

$$
\text { Crystallinity }(\%)=100 \times \frac{\Delta H_{m}}{f \Delta H_{m}^{0}}
$$

Where $\mathrm{f}$ is $\mathrm{P}(3 \mathrm{HB})$ fraction in mass on the composite, $\Delta H_{m}{ }^{\circ}$ is the melting enthalpy for a $100 \%$ crystalline $\mathrm{P}(3 \mathrm{HB})(146 \mathrm{~J} / \mathrm{g})^{33}$.

The crystallinity of pure $\mathrm{P}(3 \mathrm{HB})$ obtained $(64.5 \%)$ is similar to values reported in the literature. El-Hadi et al. reported $60 \%$ of crystallinity calculated from DSC curves ${ }^{34}$. Crétois et al. found the same $60 \%$ of crystallinity for an aged $\mathrm{P}(3 \mathrm{HB})^{35}$. Galego et al., by means of $\mathrm{X}$-ray diffraction technique, found the crystallinity of pure $\mathrm{P}(3 \mathrm{HB})$ to be $69.0 \pm$ $0.2 \%{ }^{36}$. However, different values may be found, since PHB is very sensitive to secondary crystallization and physical aging, which may increase crystallinity ${ }^{35,37,38}$.

According to what is presented on Table 2, the crystallinity decreased with addition of ND, regardless of ND content; it can be justified by presence of aggregation of ND on all formulation, obstructing their polymeric chains mobility, which limits $\mathrm{P}(3 \mathrm{HB})$ crystallization. Jee and Lee also found the crystallinity to decrease due aggregation for higher loads of ND ( 7 and $9 \mathrm{wt} \%$ ) in a matrix of low-density polyethylene

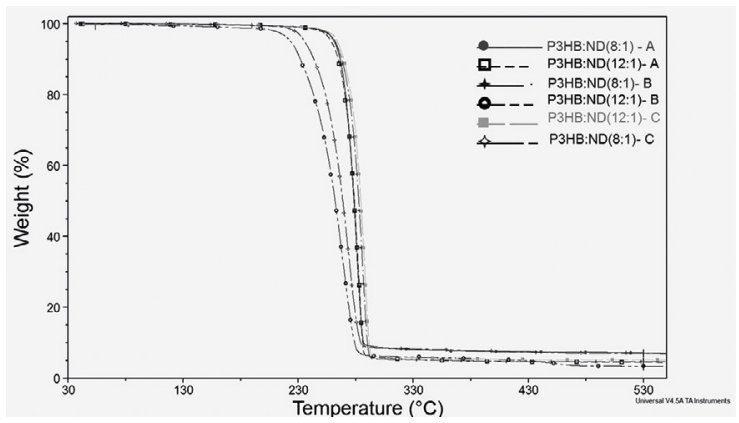

Figure 2: TGA curve from samples taken from different regions of $\mathrm{P}(3 \mathrm{HB}): \mathrm{ND}(8: 1)$ and $(12: 1)$ specimen.

Table 2: Melting enthalpy, crystallinity and melting temperature, obtained by DSC for raw $\mathrm{P}(3 \mathrm{HB})$ and the three composite formulation.

\begin{tabular}{lccc}
\hline Formulation & $\begin{array}{c}\text { Melting } \\
\text { Enthalpy } \\
(\Delta \mathrm{Hm})(\mathrm{J} / \mathrm{g})\end{array}$ & $\begin{array}{c}\text { Crystallinity } \\
(\%)\end{array}$ & $\begin{array}{c}\text { Melting } \\
\text { Temperature } \\
(\mathrm{Tm})\left({ }^{\circ} \mathrm{C}\right)\end{array}$ \\
\hline $\mathrm{P}(3 \mathrm{HB})$ & 94.1 & 64.5 & 179.3 \\
$\mathrm{P}(3 \mathrm{HB}): \mathrm{ND}(16: 1)$ & 85.9 & 62.8 & 170.8 \\
$\mathrm{P}(3 \mathrm{HB}): \mathrm{ND}(12: 1)$ & 81.7 & 61.0 & 170.4 \\
$\mathrm{P}(3 \mathrm{HB}): \mathrm{ND}(8: 1)$ & 84.0 & 62.8 & 170.6 \\
\hline
\end{tabular}


$(\mathrm{LDPE})^{39}$. Other authors found that adding small loads of welldispersed ND increase crystallinity of $\mathrm{PLA}^{26}$ and polyvinyl alcohol (PVA) ${ }^{19,40}$, arguing that it acts as nucleating agents. For same reasons presented for crystallization behavior, the melting temperature for the three compositions are lower than raw $\mathrm{P}(3 \mathrm{HB})$; and it remains almost the same among the three compositions.

In the Figure 3 is shown the micrographs for the three formulations, where the regions where ND is agglomerated are indicated. ND has a high tendency to agglomerate, due its large surface area/volume and the many functional groups presented on its surface (hydroxyl, carbonyl, ether, amine, amide, etc. $)^{41,42}$. In addition to the agglomerates, other features were identified on the micrographs. On the specimens surface of fracture are shown cracks, voids and indications of particles debonding; they are represented in Figure 4 as C, V and PD, respectively. These defects limit the potential to increase the biocomposite properties, they may even weaken it.

Dynamic mechanical analysis (DMA) were done for the three formulations and raw $\mathrm{P}(3 \mathrm{HB})$. The storage modulus per temperature and tangent of delta per temperature curves are shown in Figure 5. Even though $\mathrm{P}(3 \mathrm{HB}) \mathrm{ND}(8: 1)$ has the highest ND content, this formulation presents the lowest storage modulus. From what is presented in Figure 3(A), for this formulation, the ND are arranged as large agglomerates. Thus, there isn't an effective restriction on the polymer chain mobility; instead, as its storage modulus is slightly inferior of raw $\mathrm{P}(3 \mathrm{HB})$, we can conclude that these large agglomerates acted as a stress concentrator, weakening the composite, decreasing its stiffness.

The formulation that presented the highest storage modulus was $\mathrm{P}(3 \mathrm{HB}): \mathrm{ND}(12: 1)$, according to what is shown in Figure 3(B), agglomerates is also present on the surface; however, they are smaller and more homogeneously distributed on the matrix, promoting a better anchorage of polymeric chains. The $\mathrm{P}(3 \mathrm{HB}) \mathrm{ND}(16: 1)$ formulation, also presents a storage modulus higher than raw $\mathrm{P}(3 \mathrm{HB})$, showing that it also restrain the polymeric chains mobility. However, since it has a lower content of ND, there is fewer anchorage regions; thus, lower stiffness and storage modulus. For the same reasons presented for storage modulus, glass transition temperature $\left(\mathrm{T}_{\mathrm{g}}\right)$, defined by the temperature where occurs the peak on the tan $\delta$ per temperature curve ${ }^{36}$, the $\mathrm{P}(3 \mathrm{HB}): \mathrm{ND}(12: 1)$ presents the highest $\mathrm{T}_{\mathrm{g}}$, followed by $\mathrm{P}(3 \mathrm{HB}): \mathrm{ND}(16: 1)$ and $\mathrm{P}(3 \mathrm{HB}): \mathrm{ND}(8: 1)$. The values are presented on Table 3 .
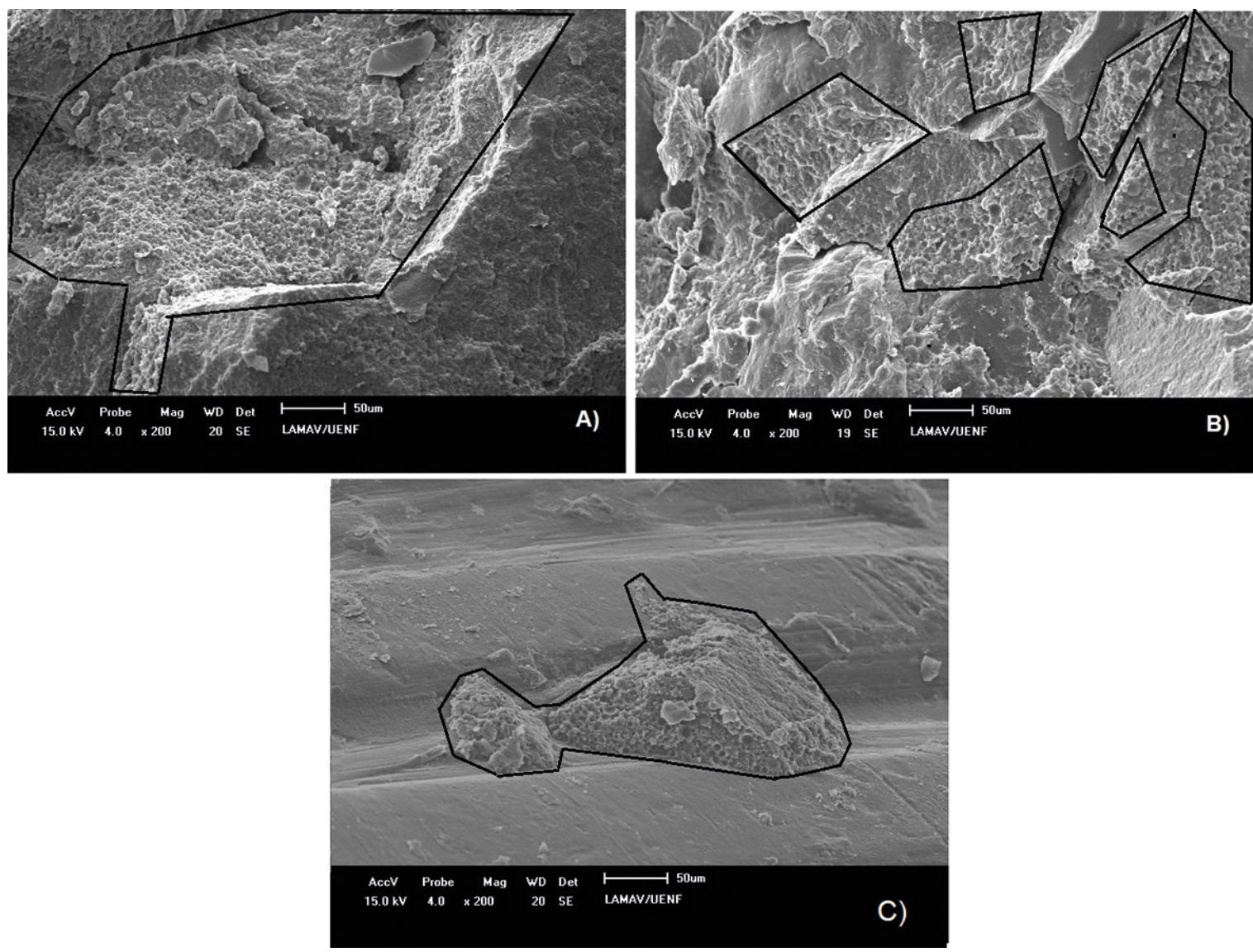

Figure 3: SEM micrographs with magnification of 200x for: $A) \mathrm{P}(3 \mathrm{HB}): \mathrm{ND}(8: 1)$; $\mathrm{B}) \mathrm{P}(3 \mathrm{HB}): \mathrm{ND}(12: 1)$; $\mathrm{C}) \mathrm{P}(3 \mathrm{HB}): \mathrm{ND}(16: 1)$. 

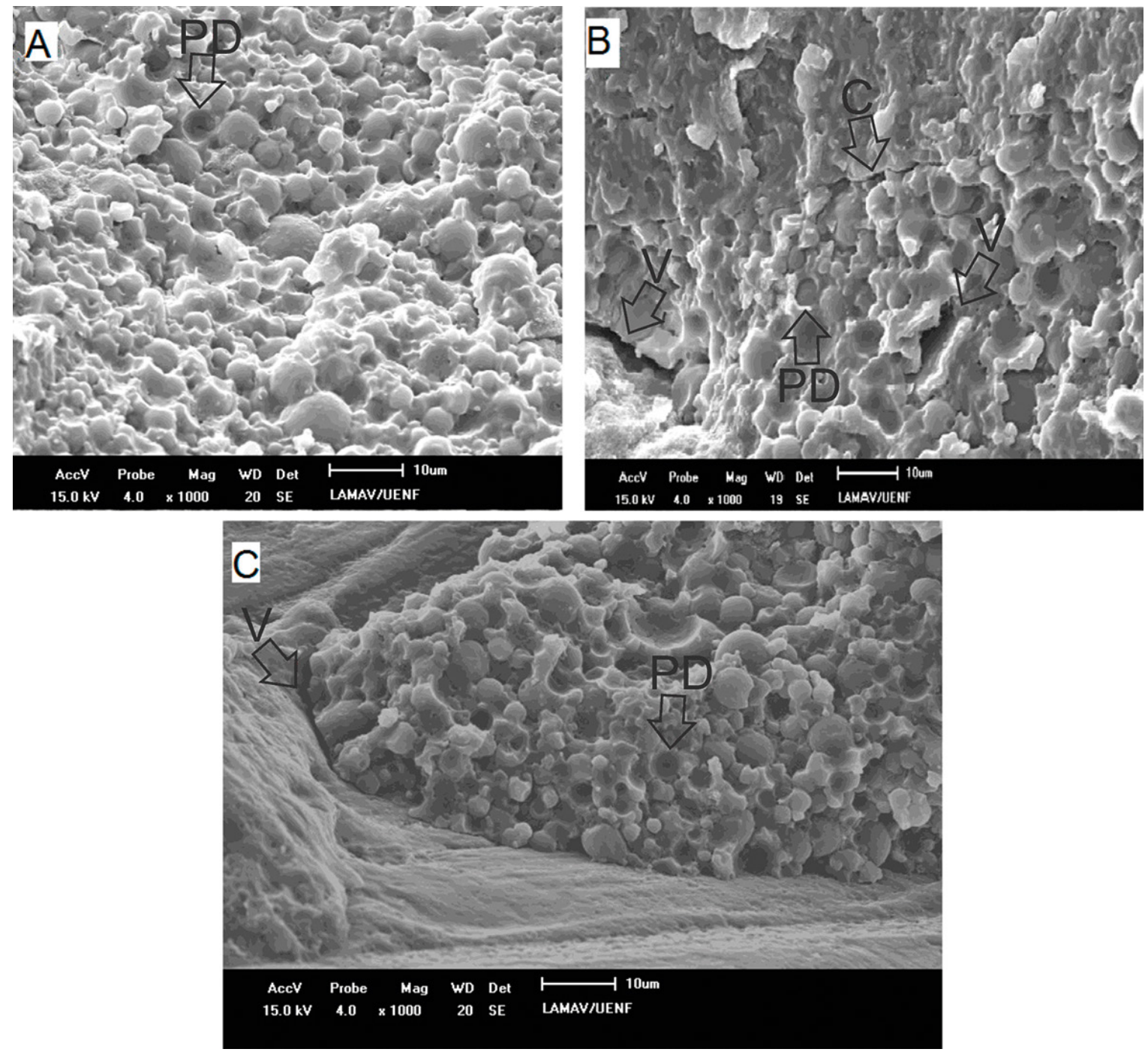

Figure 4: Sample surface micrographs with magnification of $1000 x$ for formulations: $A) P(3 H B): N D(8: 1), B) P(3 H B): N D(12: 1)$ and C) $\mathrm{P}(3 \mathrm{HB}): \mathrm{ND}(16: 1)$. The abbreviation $\mathrm{C}, \mathrm{V}$ and $\mathrm{PD}$, stands for: cracks, voids and particle debonding, respectively.

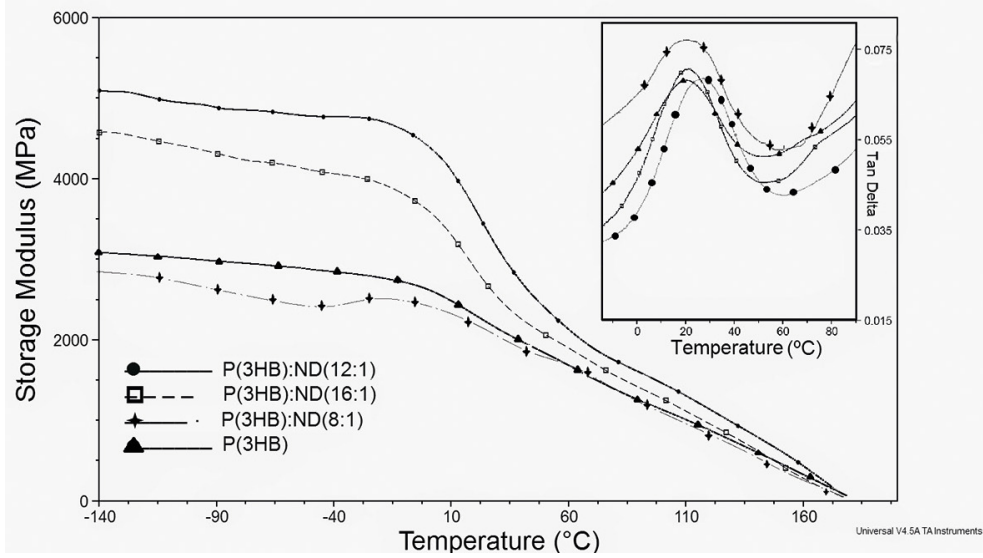

Figure 5: Storage modulus and tan delta per temperature curves for all formulations. 
Table 3: Properties obtained by DMA for different formulations.

\begin{tabular}{lccc}
\hline Formulation & $\begin{array}{c}\text { Storage Modulus (MPa) } \\
\text { Glassy Region }\end{array}$ & $\begin{array}{c}\text { Storage Modulus (MPa) } 35{ }^{\circ} \mathrm{C} \\
\text { (3lass Transition Temperature } \\
(\mathrm{Tg})\left({ }^{\circ} \mathrm{C}\right)\end{array}$ & 2054 \\
$\mathrm{P}(3 \mathrm{HB}): \mathrm{ND}(16: 1)$ & 3067 & 2906 & 21.8 \\
$\mathrm{P}(3 \mathrm{HB}): \mathrm{ND}(12: 1)$ & 4580 & 2373 & 27.0 \\
$\mathrm{P}(3 \mathrm{HB}): \mathrm{ND}(8: 1)$ & 5093 & 1964 & 19.4 \\
\hline
\end{tabular}

\section{Conclusions}

The analyses performed allowed to conclude that the content of ND indicated by TGA differs from the content added to the solution before encapsulation; due a possible loss of material during the encapsulation phase and heterogeneous distribution of ND in the composite; therefore, the ND content of the sample taken from the specimen for analysis is likely to differ from the mean value present in the composite, since it may correspond to the region poor or rich on ND. Due the presence of agglomerates, there was a decrease on crystallinity and melting temperature for all formulations, more pronounced for $\mathrm{P}(3 \mathrm{HB}): \mathrm{ND}(8: 1)$. The formulation $\mathrm{P}(3 \mathrm{HB}): \mathrm{ND}(12: 1)$ presented higher storage modulus and $\mathrm{T}_{\mathrm{g}}$, promoting a better anchoring of polymeric chains, justified by its agglomerates more homogeneously distributed on the matrix. From the SEM micrographs of the specimen fracture surface was identified cracks, voids and particles debonding, which limited the properties optimization.

\section{Acknowledgments}

We would like to thank to FAPERJ, CAPES and CNPQ for the financial support.

\section{References}

1. Jordan J, Jacob KI, Tannenbaum R, Sharaf MA, Jasiuk I. Experimental trends in polymer nanocomposites-a review. Materials Science and Engineering: A. 2005;393(1-2):1-11.

2. Paul DR, Robeson LM. Polymer nanotechnology: Nanocomposites. Polymer. 2008;49(15):3187-3204.

3. Causa F, Netti PA, Ambrosio L, Ciapetti G, Baldini N, Pagani S, et al. Poly- $\varepsilon$-caprolactone/hydroxyapatite composites for bone regeneration: In vitro characterization and human osteoblast response. Journal of Biomedical Materials Research. Part A. 2006;76(1):151-162.

4. Mochalin VN, Gogotsi Y. Nanodiamond-polymer composites. Diamond and Related Materials. 2015;58:161-171.

5. Qiao R, Brinson LC. Simulation of interphase percolation and gradients in polymer nanocomposites. Composites Science and Technology. 2009;69(3-4):491-499.

6. Katti KS. Biomaterials in total joint replacement. Colloids and Surfaces B: Biointerfaces. 2004;39(3):133-142.

7. Ramakrishna S, Huang ZM, Kumar GV, Batchelor AW, Mayer J. An Introduction to Biocomposites. London: Imperial College Press; 2004. 223 p.
8. Middleton JC, Tipton AJ. Synthetic biodegradable polymers as orthopedic devices. Biomaterials. 2000;21(23):23352246.

9. Armentano I, Dottori M, Fortunati E, Mattioli S, Kenny JM. Biodegradable polymer matrix nanocomposites for tissue engineering: A review. Polymer Degradation and Stability. 2010;95(11):2126-2146.

10. Braunegg G, Lefebvre G, Genser KF. Polyhydroxyalkanoates, biopolyesters from renewable resources: Physiological and engineering aspects. Journal of Biotechnology. 1998;65(23):127-161.

11. Nair LS, Laurencin CT. Biodegradable polymers as biomaterials. Progress in Polymer Science. 2007;32(89):762-798.

12. Meischel M, Eichler J, Martinelli E, Karr U, Weigel J, Schmöller G, et al. Adhesive strength of bone-implant interfaces and in-vivo degradation of PHB composites for load-bearing applications. Journal of the Mechanical Behavior of Biomedical Materials. 2016;53:104-118.

13. Bonartsev AP, Iordanskii AL, Bonartseva GA, Zaikov GE. Biodegradation and medical application of microbial poly(3-hydroxybutyrate). Journal of the Balkan Tribological Association. 2008;14(3):359-395.

14. Doyle C, Tanner ET, Bonfield W. In vitro and in vivo evaluation of polyhydroxybutyrate and of polyhydroxybutyrate reinforced with hydroxyapatite. Biomaterials. 1991;12(9):841-847.

15. Gredes T, Gedrange T, Hinüber C, Gelinsky M, KunertKeil C. Histological and molecular-biological analyses of poly(3-hydroxybutyrate) (PHB) patches for enhancement of bone regeneration. Annals of Anatomy. 2015;199:36-42.

16. Krueger A. Diamond Nanoparticles: Jewels for Chemistry and Physics. Advanced Materials. 2008;20(12):2445-2449.

17. Mochalin VN, Shenderova O, Ho D, Gogotsi Y. The properties and applications of nanodiamonds. Nature Nanotechnology. 2012;7(1):11-23.

18. Schrand A, Hens SAC, Shenderova O. Nanodiamond Particles: Properties and Perspectives for Bioapplications. Critical Reviews in Solid State and Materials Sciences. 2009;34(1-2):18-74.

19. Maitra U, Prasad KE, Ramamurty U, Rao CNR. Mechanical properties of nanodiamond-reinforced polymer-matrix composites. Solid State Communications. 2009;149(3940):1693-1697.

20. Artemov AS. Polishing Nanodiamonds. Physics of the Solid State. 2004;46(4):687-695. 
21. Burkat GK, Fujimura T, Dolmatov VY, Orlova EA, Veretennikova MV. Preparation of composite electrochemical nickel-diamond and iron-diamond coatings in the presence of detonation synthesis nanodiamonds. Diamond and Related Materials. 2005;14(11-12):1761-1764.

22. Behler KD, Stravato A, Mochalin V, Korneva G, Yushin G, Gogotsi Y. Nanodiamond-Polymer Composite Fibers and Coatings. ACS Nano. 2009;3(2):363-369.

23. Zhu Y, Li J, Li W, Zhang Y, Yang X, Chen N, et al. The Biocompatibility of Nanodiamonds and Their Application in Drug Delivery Systems. Theranostics. 2012;2(3):302-312.

24. Zhang Q, Mochalin VN, Neitzel I, Knoke IY, Han J, Klug CA, et al. Fluorescent PLLA-nanodiamond composites for bone tissue engineering. Biomaterials. 2011;32(1):87-94.

25. Zhang Q, Mochalin VN, Neitzel I, Hazeli K, Niu J, Kontsos A, et al. Mechanical properties and biomineralization of multifunctional nanodiamond-PLLA composites for bone tissue engineering. Biomaterials. 2012;33(20):5067-5075.

26. Zhao YQ, Lau KT, Kim JK, Xu CL, Zhao DD, Li HL. Nanodiamond/poly (lactic acid) nanocomposites: Effect of nanodiamond on structure and properties of poly (lactic acid). Composites Part B: Engineering. 2010;41(8):646-653.

27. Cao L, Hou Y, Lafdi K, Urmey K. Fluorescent composite scaffolds made of nanodiamonds/polycaprolactone. Chemical Physics Letters. 2015;641:123-128.

28. Sun Y, Finne-Wistrand A, Waag T, Xing Z, Yassin M, Yamamoto A, et al. Reinforced Degradable Biocomposite by Homogenously Distributed Functionalized Nanodiamond Particles. Macromolecular Materials and Engineering. 2015;300(4):436-447.

29. Akita S, Einaga Y, Miyaki Y, Fujita H. Solution Properties of Poly(D- $\beta$-hydroxybutyrate). 1. Biosynthesis and Characterization. Macromolecules. 1976;9(5):774-780.

30. Poley LH, Siqueira APL, da Silva MG, Sanchez R, Prioli R, Mansanares AM, et al. Photothermal methods and atomic force microscopy images applied to the study of poly(3-hydroxybutyrate) and poly(3-hydroxybutyrate-co-3-hydroxyvalerate) dense membranes. Journal of Applied Polymer Science. 2005;97(4):1491-1497.

31. Sundar LS, Singh MK, Sousa ACM. Experimental thermal conductivity and viscosity of nanodiamond-based propylene glycol and water mixtures. Diamond and Related Materials. 2016;69:49-60.
32. Schreck KM, Hillmyer MA. Block copolymers and melt blends of polylactide with Nodax microbial polyesters: preparation and mechanical properties. Journal of Biotechnology. 2007;132(3):287295.

33. Barham PJ, Keller A, Otun EL, Holmes PA. Crystallization and morphology of a bacterial thermoplastic: poly-3-hydroxybutyrate. Journal of Materials Science. 1984;19(9):2781-2794.

34. El-Hadi A, Schnabel R, Straube E, Müller G, Henning S. Correlation between degree of crystallinity, morphology, glass temperature, mechanical properties and biodegradation of poly (3-hydroxyalkanoate) PHAs and their blends. Polymer Testing. 2002;21(6):665-674.

35. Crétois R, Chenal J-M, Sheibat-Othman N, Monnier A, Martin $\mathrm{C}$, Astruz O, et al. Physical explanations about the improvement of PolyHydroxyButyrate ductility: Hidden effect of plasticizer on physical ageing. Polymer. 2016;102:176-182.

36. Galego N, Rozsa C, Sánchez R, Fung J, Vázquez A, Santo Tomás J. Characterization and application of poly( $\beta$-hydroxyalkanoates) family as composite biomaterials. Polymer Testing. 2000;19(5):485492.

37. Kurusu RS, Siliki CA, David E, Demarquette NR, Gauthier C, Chenal JM. Incorporation of plasticizers in sugarcane-based poly(3-hydroxybutyrate)(PHB): Changes in microstructure and properties through ageing and annealing. Industrial Crops and Products. 2015;72:166-174.

38. Biddlestone F, Harris A, Hay JN, Hammond T. The physical ageing of amorphous poly(hydroxybutyrate). Polymer International. 1996;39(3):221-229.

39. Jee AY, Lee M. Thermal and mechanical properties of alkylfunctionalized nanodiamond composites. Current Applied Physics. 2011;11(5):1183-1187.

40. Morimune S, Kotera M, Nishino T, Goto K, Hata K. Poly(vinyl alcohol) Nanocomposites with Nanodiamond. Macromolecules. 2011;44(11):4415-4421.

41. Kulakova II. Surface chemistry of nanodiamonds. Physics of the Solid State. 2004;46(4):636-643.

42. Osswald S, Yushin G, Mochalin V, Kucheyev SO, Gogotsi Y. Control of sp $2 / \mathrm{sp}^{3}$ Carbon Ratio and Surface Chemistry of Nanodiamond Powders by Selective Oxidation in Air. Journal of the American Chemical Society. 2006;128(35):11635-11642. 